\title{
Endotoxin Analysis: Correlation Between Biological and Chemical Methods
}

\author{
Emilia Paba*, Alessandra Chiominto, Anna Maria Marcelloni, Francesca Tombolini, Enrico \\ Paci and Giovanna Tranfo
}

Department of Occupational and Environmental Medicine, Epidemiology and Hygiene, National Institute for Insurance against Accidents at Work (INAIL), Monte Porzio Catone (Rome), Italy

*Corresponding author: Emilia PABA, Department of Occupational and Environmental Medicine, Epidemiology and Hygiene,

National Institute for Insurance against Accidents at Work (INAIL), Monte Porzio Catone (Rome), Italy

\section{ARTICLE INFO}

Received: 崑 July 08, 2019

Published: 慧 July 16, 2019

Citation: Emilia P, Alessandra C, Anna Maria M, Francesca T, Enrico P, et al., Endotoxin Analysis: Correlation Between Biological and Chemical Methods. Biomed J Sci \& Tech Res 19(4)2019. BJSTR. MS.ID.003339.

Keywords: Endotoxin; Lipopolysaccharide; Gram-Negative; 3-Hydroxy Fatty Acids; HPLC-MS/MS; LAL Test

\begin{abstract}
Assessment of occupational exposure to airborne endotoxins was studied for several years but still different procedures are used for sampling and analysis. Among analytical methods LAL test is the most used. A different approach is represented by chemical analyses, based on the detection of the $\beta$ - hydroxy fatty acids, as markers of lipopolysaccharide (LPS). In this study an analytical method using HPLC-MS/MS was applied to quantify the content of $\beta$ - hydroxy-dodecanoic $\left(3-\mathrm{OH} \mathrm{C}_{12}\right.$ ) and $\beta$-hydroxytetradecanoic $\left(3-\mathrm{OH} \mathrm{C}_{14}\right.$ ) acids in thirteen Gram- negative bacterial strains. In order to compare biological and chemical results cell suspensions were analyzed also by Kinetic Chromogenic LAL test. The results obtained by HPLC-MS/MS show that three samples did not contain $3-\mathrm{OH} \mathrm{C}_{12}$ at all, while $3-\mathrm{OH} \mathrm{C} \mathrm{C}_{14}$ was measured in a concentration range from 11.1 to $4007.5 \mu \mathrm{g} / \mathrm{L}$. Endotoxin concentration measured by LAL assay was in the range of $10^{2}-10^{3} \mu \mathrm{g} / \mathrm{L}$. Pearson's test showed that the sum of fatty acids by HPLC-MS/MS correlates positively with the LAL Test $(\mathrm{r}=0.79)$ confirming that it can be considered a reliable marker of endotoxin contamination. Principal Component Analysis (PCA) confirms above results and provides additional information grouping microorganisms related with each other on the basis of their biochemical features, habitat and disease spectra.
\end{abstract}

Abbreviations: PCA: Principal Component Analysis, ODTS: Organic Dust Toxic Syndrome, OEL: Occupational Exposure Limit, LAL: Limulus Amebocyte Lysate, GC/MS: Gas Chromatography Coupled To Mass Spectrometry, HPLC-MS/MS: High Performance Liquid Chromatography Coupled To Tandem Mass Spectrometry, ATCC: American Type Culture Collection, NA: Nutrient Agar, PFW: Pyrogen Free Water, CSE: Control Standard Endotoxin

\section{Introduction}

Endotoxins are unavoidable ubiquitous microbiological contaminants; they may be present in food, environment and clinical products. Their inhalation can poses serious risks to human health, from respiratory and general symptoms such as fever, coughing, irritation and chest congestion up to chronic bronchitis and organic dust toxic syndrome (ODTS) [1,2]. For this reason, assessment of exposure to these components was studied for several years, especially in occupational environments, but a large number of different procedures are still used for sampling and analysis; this makes difficult to compare results and to establish an Occupational Exposure Limit (OEL) for these biological agents [3-5]. Among analytical methods, the most used is the Limulus Amebocyte Lysate (LAL) test, in its kinetic chromogenic version, which measures the relative reactivity of endotoxins with limulus lysate providing rapid and sensitive results. However, several critical aspects of this test are reported in literature: the cross-reactivity with other types of biomolecules such as $\beta$-d-glucans and peptidoglycans, the underestimation of the results due to a fraction non-water soluble not detectable with LAL test and the influence of endotoxin content after repeated freezing/thawing of samples [6,7]. Furthermore, this bioassay may underestimate endotoxin exposure because cellbound endotoxins, that may be associated with respiratory disease, are not detected [8].

A different approach to measure endotoxin is represented by chemical analyses, which are based on the detection of the $\beta$-hydroxy fatty acids (3-OHFAs), the major components of lipid 
A moiety of lipopolysaccharide, as chemical markers of LPS. The analytical methods that can be used for this purpose may be the Gas Chromatography coupled to Mass Spectrometry (GC/MS) and the High Performance Liquid Chromatography coupled to Tandem Mass Spectrometry (HPLC-MS/MS): both techniques focus on the quantification of biomarkers of endotoxins, 3-hydroxy fatty acids in the lipid A portion of LPS. Unlike bioassays, chemical analysis of 3-OHFAs allows the determination of both cellbound and non-cell-bound endotoxins, since they are chemically extracted from lipid A. Chemical methods are certainly more labor intensive and relatively expensive comparing with bioassays, but understanding the chemistry of endotoxins may help also in explaining the development of correlated diseases, and ultimately, for interventions [9]. Several methods involving GC/MS technique have been studied or developed $[10,11]$, but comparison with the bioassay reveals relatively weak correlations: GC/ MS results are often higher than those obtained with the biological methods. In addition, GC/MS requires a long preparation time due to the need for derivatization of the sample.

HPLC-MS/MS has the advantage to be more suitable for the analysis of aqueous samples, not requiring derivatization and not exposing the analytes to high temperatures, thus avoiding the risk of degradation. Besides, the use of the tandem mass spectrometry detection increases its sensitivity and specificity. In a previous paper we presented a new analytical method by HPLC-MS/MS to quantify $\beta$ - hydroxy-dodecanoic $\left(3-\mathrm{OH} \mathrm{C}_{12}\right.$, lauric acid) and $\beta$-hydroxy-tetradecanoic (3-OH C $\mathrm{C}_{14}$, myristic acid) acids and a pilot study was carried out on four ATCC Gram-negative bacteria and two fungi [12]. The choice of these acids is due to the fact that previous reports indicate that shorter-chains $\left(C_{10}-C_{14}\right) \beta$ - hydroxyfatty acids are positively correlated with endotoxin activity in the Limulus bioassay while longer-chain $\left(\mathrm{C}_{16}-\mathrm{C}_{18}\right)$ 3-OHFAs tend to have lower or even no correlation [13]. It was also suggested that $\mathrm{C}_{12}-\mathrm{C}_{14}$ 3-OHFAs may elicit more significant potent immunological effects in humans [14]. The main objective of this study was to evaluate the correlation between biological and chemical methods for endotoxin analysis comparing chemical results (HPLC-MS/MS) to LAL assay on thirteen Gram-negative bacterial strains of clinical and occupational interest, obtained from American Type Culture Collection (ATCC).

\section{Materials and Methods}

ATCC Gram-negative bacterial strains used in this study were: Ochrobacter anthropi-19286, Proteus mirabilis-15290, Comamonas acidovorans-15668, Pseudomonas stutzeri-53817, Flavimonas horizihabitans-35564, Acinetobacter shindleriBAA-618, Sphingomonas paucimobilis-29837, Aeromonas salmonicida-27013, Pseudomonas luteola-43330, Aeromonas hydrophila-35654, Pseudomonas aeruginosa-15442, Escherichia coli-8739 and Enterobacter aerogenes-35029, purchased from D.I.D. S.p.A, Biogenetics S.r.l. and Remel Europe Ltd. Each strain was inoculated on Nutrient Agar (NA) and incubated according to growth conditions of ATCC. Then, cell suspensions with Pyrogen Free Water (PFW) were prepared, read by spectrophotometer (OD550) and inoculated in NA to count the Colony Forming Units (final concentration $\approx 1,2 \times 10^{9} \mathrm{CFU} / \mathrm{ml}$ ). Bacterial cells were mechanically lysed by vortexing at a maximum speed for $5 \mathrm{~min}$ with apyrogenic glass beads ( $0.2 \mathrm{~mm}$ in diameter), with intermediate cooling in ice. All samples were tested both by kinetic QCL-LAL assay and HPLC-MS/MS.

\section{Kinetic QCL-LAL Assay}

A volume of $100 \mu \mathrm{l}$ of serial 10 -fold dilutions (1, 0.1, 0.01, 0.001, $0.0001,0.00001$ ) of each suspension was analyzed by Kinetic QCLLAL assay (Lonza Walkersville, MD USA) and interpreted against a 5-point (concentration range from 0.005 to $50 \mathrm{EU} / \mathrm{ml}$ ) standard curves of Escherichia coli (CSE). In order to obtain information about possible enhancement or inhibition reactions of the LAL assay, a replicate of each sample was spiked with a CSE standard ( $5 \mathrm{EU} / \mathrm{ml}$ final activity). The recovery of spiked samples was in the range of 50-200\%; otherwise the measurement was repeated. Results are reported as $\mu \mathrm{g} / \mathrm{L}$.

\section{HPLC-MS/MS Method}

The samples were analyzed by HPLC-MS/MS technique for detection of $3-\mathrm{OH} \mathrm{C}_{12}$ and $3-\mathrm{OH} \mathrm{C} \mathrm{C}_{14}$ according to the procedure previously published [12]. Briefly, fatty acids were extracted, after alcaline hydrolysis, with n-hexane and extracts were dried in evaporator for 30 minutes at $60^{\circ} \mathrm{C}$. The residue was dissolved in $0.5 \mathrm{ml}$ of acetonitrile and, after filtration on $0.2 \mu \mathrm{m}$ Anotop10 IC membrane filters, was injected into the HPLC-MS/MS system. Standard solutions of 3-OH C $\mathrm{C}_{12}, 3-\mathrm{OH} \mathrm{C} \mathrm{C}_{14}$ acids and 3-hydroxy-tridecanoic acid (as internal standard) were prepared in acetonitrile; from these solutions, by further dilutions, the calibration and quality control (QC) samples were prepared. The HPLC device was a Perkin Elmer series 200 , equipped with a Supelco Hypersyl BDSC8 $(150 \times 4.6,5 \mu \mathrm{m})$ chromatographic column, maintained at $40^{\circ} \mathrm{C}$, with mobile phase consisting of a gradient of acetonitrile and acetic acid $1 \% \mathrm{v} / \mathrm{v}$ in water; run time was 10 minutes at a flow rate of $1000 \mu \mathrm{l} / \mathrm{min}$. The detector was an AB/Sciex API 4000 triple quadrupole mass spectrometer, equipped with a Turbo Ion Spray (TIS) probe working in the negative ion, multiple reaction monitoring (MRM) mode; the $\mathrm{m} / \mathrm{z}$ ion transitions (precursor $\rightarrow$ product), corresponding to the loss of a fragment of 46 u.m.a, typical of $\beta$-hydroxy fatty acids, were monitored for both the qualitative and the quantitative analysis. The 1.4 Analyst ${ }^{\circ}$ software was used to process the quantitative data. The method was validated in the range 10-1000 $\mu \mathrm{g} / \mathrm{L}$ for both analytes. Results are expressed in $\mu \mathrm{g} / \mathrm{L}$ of fatty acids.

\section{Statistical Analysis}

Results were analyzed by Principal Component Analysis (PCA). In order to know how all the variables are correlated, this statistical procedure was performed using $\mathrm{R}$ software package 
[15] on the original dataset composed of 13 rows (ATCC bacterial strains) and 4 columns (LAL assay, $3-\mathrm{OH} \mathrm{C} \mathrm{C}_{12}, 3-\mathrm{OH} \mathrm{C} \mathrm{C}_{14}$ and the sum of 3-OH C $\mathrm{C}_{12}$ and $3-\mathrm{OH} \mathrm{C} \mathrm{C}_{14}$ ). Loadings and scores of the two principal components were calculated and they explain $65 \%$ and $33 \%$ of the total variance, respectively [16]. In order to evaluate the correlation between variables, Pearson's coefficients were also calculated using the software R.

\section{Results}

The concentrations of the two $\beta$-hydroxy-fatty acids and endotoxins found in the thirteen bacterial strains are reported in Table 1. Three samples did not contain $3-\mathrm{OH} \mathrm{C}_{12}$ at all, while $3-0 \mathrm{C}_{14}$ was always present in a concentration range from 11.1 to $4007.5 \mu \mathrm{g} / \mathrm{L}$. The ratio between $3-\mathrm{OHC}_{12}$ and $3-\mathrm{OH} \mathrm{C}_{14}$ was extremely variable; the concentration percentage of this last, respect to the other acid, ranged from $6 \%$ to $100 \%$. The concentration of endotoxin measured by LAL test was of the order of $10^{2}-10^{3} \mu \mathrm{g} / \mathrm{L}$ with the lowest levels in Sphingomonas paucimobilis $(2 \mu \mathrm{g} / \mathrm{L})$ and in two species belonging to Pseudomonas genus (P. aeruginosa and P. luteola; 49 and $70 \mu \mathrm{g} / \mathrm{L}$ respectively). The highest concentration was found in Acinetobacter shindleri $(7800 \mu \mathrm{g} / \mathrm{L})$. Statistical analysis performed using Pearson's test Table 2, showed a linear correlation between all variables: the strongest correlation ( $\mathrm{r}=0.79$ ) was observed between endotoxins measured by LAL test and the sum of the two fatty acids concentrations determined by HPLC-MS/ MS. PCA analysis confirmed these results Figure 1. Moving along the first (PC1) versus the second Principal Component (PC2), endotoxins and $3-0 \mathrm{H} \mathrm{C}_{12}+3-\mathrm{OH} \mathrm{C} \mathrm{C}_{14}$ concentrations are grouped together confirming that endotoxin levels positively correlate with the sum of the two fatty acids measured.

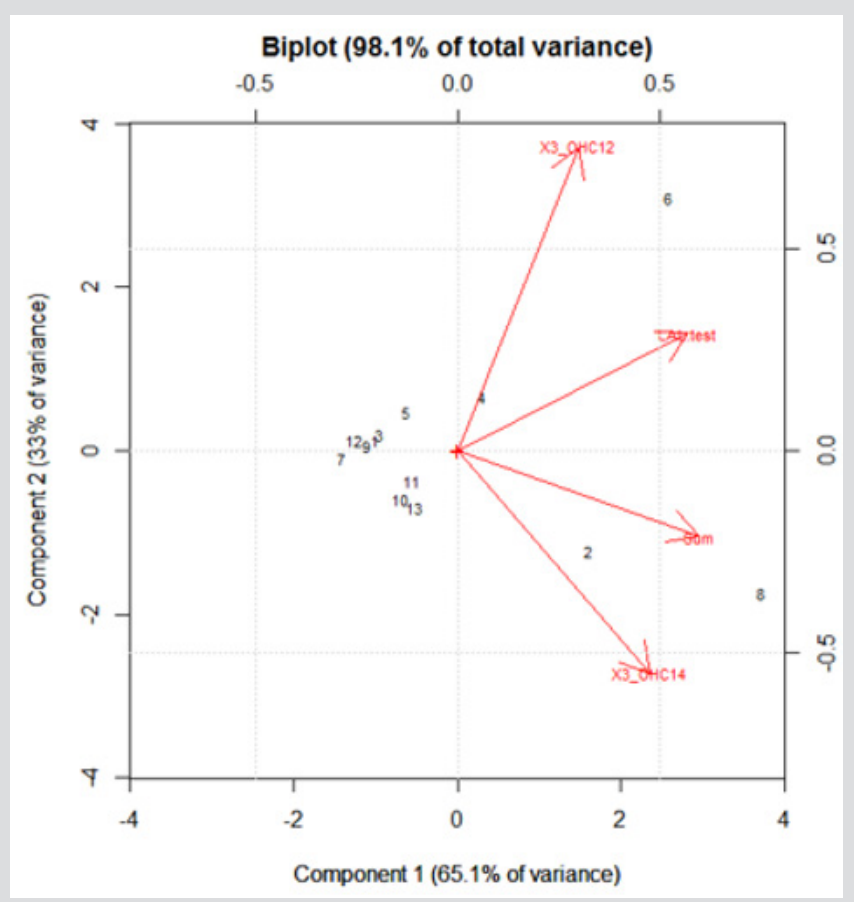

Figure 1: PCA analysis results (variables: $3-\mathrm{OH} \mathrm{C} \mathrm{C}_{12}, 3-\mathrm{OH} \mathrm{C}_{14^{\prime}}$ sum, LAL test).

Table 1: Concentrations $(\mu \mathrm{g} / \mathrm{L})$ of 3-OH C $\mathrm{C}_{12}$ and 3-OH C $\mathrm{C}_{14}$ by HPLC-MS/MS, of endotoxin by LAL assay.

\begin{tabular}{|c|c|c|c|c|}
\hline N. & Bacterial Strains & $3-0 \mathrm{C} \mathrm{C}_{12}$ & 3-Oh C & Endotoxin \\
\hline 1 & Ochrobacter anthropi & 12.5 & 22.1 & 1800 \\
\hline 2 & Proteus mirabilis & 37.3 & 2500 & 3400 \\
\hline 3 & Comamonas acidovorans & 49.8 & 17.1 & 1900 \\
\hline 4 & Pseudomonas stutzeri & 579 & 505.5 & 3000 \\
\hline 5 & Flavimonas horizihabitans & 397.7 & 131.5 & 1300 \\
\hline 6 & Acinetobacter shindleri & 1932.5 & 213 & 7800 \\
\hline 7 & Sphingomonas paucimobilis & 9.6 & 30.7 & 2 \\
\hline 8 & Aeromonas salmonicida & 114.8 & 4007.5 & 6400 \\
\hline 9 & Pseudomonas luteola & 88.9 & 82.9 & 70 \\
\hline 10 & Escherichia coli & 0 & 816.5 & 122 \\
\hline 11 & Aeromonas hydrophila & 0 & 673 & 127 \\
\hline 12 & Pseudomonas aeruginosa & 166.5 & 11.1 & 49 \\
\hline 13 & Enterobacter aerogenes & 0 & 998.5 & 192 \\
\hline
\end{tabular}


Table 2: Pearson's correlation values.

\begin{tabular}{|c|c|}
\hline Variables & Lal Test \\
\hline $3-\mathrm{OH} \mathrm{C}_{12}$ & 0.70 \\
\hline $3-\mathrm{OH} \mathrm{C}_{14}$ & 0.50 \\
\hline $3-\mathrm{OH} \mathrm{C}_{12}+3-\mathrm{OH} \mathrm{C}_{14}$ & 0.79 \\
\hline
\end{tabular}

PCA results provided additional information on the grouping of microorganisms, placing E. coli, A. hydrophila and E. aerogenes (strains number 10,11, 13 respectively) on the opposite side from the variables $3-\mathrm{OH} \mathrm{C}_{12}$ and endotoxin. These bacteria contain only the myristic acid and low levels of endotoxin. P. mirabilis and A. salmonicida (strains number 2, 8) are grouped in the same direction of $3-\mathrm{OH} \mathrm{C} \mathrm{C}_{14}$ acid because they contain the absolute highest concentration of this acid (2500 and $4007.5 \mu \mathrm{g} / \mathrm{L})$. Both these groups identify bacteria belonging to Enterobacteriaceae and Aeromonadaceae families, some of which are pathogens for human and classified in the second group of risk according to the attachment XLVI of Italian Legislative Decree 81/2008.

\section{Discussion}

The HPLC-MS/MS method applied in this study allowed the direct detection of unmodified 3- hydroxy fatty acids on 13 ATCC bacterial strains showing that the myristic acid is the most represented one and the sum of the two 3-hydroxy fatty acids concentrations is confirmed to be a reliable marker of endotoxin contamination. We found this evidence also in a previous field study in which the concentration of the two fatty acids was measured in air samples collected in different workplaces in order to verify if the chemical approach can be used for the assessment of the environmental contamination from endotoxins and/or Gramnegative bacteria [17]. Our results are in line with those reported by Mishra RK et al. [18], whose indicate $\beta$ - hydroxy myristic acid (3-OH $\mathrm{C}_{14}$ ) as a chemical marker to detect endotoxins in dialysis water and also with those recently reported by Uhlig et al. [19]. The authors report that fatty acid chain lengths of 14 carbon atoms (i.e., 3-hydroxytetradecanoic acid), is the dominating congener and they highlight a correlation between endotoxin activity measured by the LAL assay and the sum of 3-hydroxydecanoic, 3-hydroxydodecanoic and 3-hydroxytetradecanoic acids in drilling mud recycling plants. In our study, although the contribution of $3-\mathrm{OH} \mathrm{C}_{12}$ to the sum of the fatty acids can be very small, it seems to have an important weight on the correlation between biological and chemical assays; the meaning of this finding should be deepened.

The bacterial species are grouped, by PCA analysis, according to criteria that are worth to be further investigated because they could provide important insights on their chemical and biological properties. Aeromonadaceae is a family of Gram-negative bacteria that morphologically resemble members of the family Enterobacteriaceae and both contain pathogens for humans; moreover, these microorganisms are closely related on the basis of their shared biochemical features (eg. nitrate reduction, fermentation of D-glucose, catalase positive, etc.), habitat (e.g. gastrointestinal treat) and disease spectra (e.g. gastroenteritis). Although additional studies are needed, the information obtained in this study can provide the basis for the application of chemical analysis to the study of the Gram-negative bacterial contamination of occupational environments.

\section{References}

1. Farokhi A, Heederik D, Smit LAM (2018) Respiratory health effects of exposure to low levels of airborne endotoxin - a systematic review. Environ Health 17(1): 14.

2. Dutkiewicz J, Mackiewicz B, Lemieszek MK, Golec M, Skórska C, et al (2016) Pantoea agglomerans: a mysterious bacterium of evil and good. Part II-- Deleterious effects: Dust-borne endotoxins and allergens--focus on grain dust, other agricultural dusts and wood dust. Ann Agric Environ Med 23(1): 6-29.

3. Wenqiong S, Xianting D (2015) Methods of endotoxin detection. JALA 20(4): 354-364.

4. Paba E, Tranfo G, Corsetti F, Marcelloni AM, Iavicoli S, et al. (2013) Indoor exposure to airborne endotoxin: a review of the literature on sampling and analysis methods. Ind Health 51(3): 237- 255.

5. Duquenne P, Marchand G, Duchaine C (2013) Measurement of endotoxins in bioaerosols at workplace: a critical review of literature and a standardization issue. Ann Occup Hyg 57(2): 137-172.

6. Eduard W, Westby MH, Larsson L (2004) Solubility of endotoxins from Escherichia coli and Pseudomonas aeruginosa. Am J Ind Med 46(4): 375377.

7. Spaan S, Doekes G, Heederik D, Thorne PS, Wouters IM, et al. (2008) Effect of Extraction and Assay Media on Analysis of Airborne Endotoxin. Appl Environ Microbiol 74 (12): 3804-3811.

8. Erridge C Bennett-Guerrero E, Poxton IR (2002) Structure and function of lipopolysaccharides. Microbes Infect 4(8): 837-851.

9. Saito R, Cranmer BK, Tessari JD, Larsson L, Mehaffy JM, et al. (2009) Recombinant factor $\mathrm{C}(\mathrm{rFC})$ assay and gas chromatography/mass spectrometry (GC/MS) analysis of endotoxin variability in four agricultural dusts. Ann Occup Hyg 53 (7): 713-722.

10. Paixãode Santana Filho A, Rodrigues Noleto G, Gorin PAJ, Merade Souza L, Iacomini M, et al. (2012) GC-MS detection and quantification of lipopolysaccharides in polysaccharides through 3-0-acetyl fatty acid methyl esters. Carboydrate Polymers 87(4): 2730-2734.

11. Binding N, Jaschinski S, Werlich S, Bletz S, Witting U, et al. (2004) Quantification of bacterial lipopolysaccharides (endotoxin) by GC-MS determination of 3-hydroxy fatty acids. J Environ Monit 6 (1): 65-70.

12. Chiominto A, Marcelloni AM, Tranfo G, Paba E, Paci E, et al. (2014) Validation of a high-performance liquid chromatography-tandem mass spectrometry method for $\beta$-hydroxy fatty acids as environmental markers of lipopolysaccharide. J Chromatogr A 1353 (1): 65-70.

13. Park JH, Szponar B, Larsson L, Gold DR, Milton DK, et al. (2004) Characterization of lipopolysaccharides present in settled house dust. Appl Environ Microbiol 70 (1): 262-267.

14. Dehus O, Hartung T, Hermann C (2006) Endotoxin evaluation of eleven lipopolysaccharides by whole blood assay does not always correlate with limulus amebocyte lysate assay. J Endot Res 12 (3): 171-180.

15. (2014) R core team, R: A language and environment for statistical computing. R Foundation for Statistical Computing, Vienna Austria.

16. Eriksson L, Byrne T, Johansson E, Trygg J, Wikstrom C, et al. (2013) PCA in: Multi and Megavariate Data analysis basic principles and application $3^{\text {rd }}$ edn. UMETRICS Sweden p: 33-54. 
17. Paci E, Marcelloni AM, Marini F, Tranfo G, Paba E, et al. (2017) Chemica Marker of Endotoxin and Gram-negative Bacteria in Occupational Health Monitoring. MESE 3(8): 525-531.

18. Mishra RK, Robert Peillard F, Ravier S, Coulomb B, Boudenne JL, et al. (2015) b-Hydroxymyristic acid as a chemical marker to detect endotoxins in dialysis water. Anal Biochem 470: 71-77.

\section{ISSN: 2574-1241}

DOI: 10.26717/BJSTR.2019.19.003339

Emilia Paba. Biomed J Sci \& Tech Res

cC) (P) This work is licensed under Creative

Submission Link: https://biomedres.us/submit-manuscript.php
19. Uhlig S, Negård M, Heldal KK, Straumfors A, Madsø L, et al. (2016) Profiling of 3-hydroxy fatty acids as environmental markers of endotoxin using liquid chromatography coupled to tandem mass spectrometry. J Chromatogr A 1434: 119-126.

$\begin{array}{ll}\text { BIOMEDICAL } & \text { Assets of Publishing with us } \\ \text { RESEARCHES } & \text { - Global archiving of articles } \\ & \text { - Immediate, unrestricted online access } \\ & \text { - Rigorous Peer Review Process } \\ \end{array}$

